\title{
Vryheid en verbond: 'n Ou-Testamentiese perspektief
}

\author{
H.F. van Rooy \\ Skool vir Bybelwetenskappe en Bybeltale \\ Potchefstroomse Universiteit vir $\mathrm{CHO}$ \\ POTCHEFSTROOM \\ E-pos: sbbhfvr@puknet.puk.ac.za
}

\begin{abstract}
Freedom and covenant: A perspective from the Old Testament

A century after the end of the Anglo-Boer War freedom remains an important issue and some people nowadays constantly ask whether they have lost their freedom in the New South Africa. This article offers an Old Testament perspective on freedom and first of all discusses the importance of blessings and curses within the framework of the covenant. This is followed by a discussion of two passages from the Old Testament - Deuteronomy 28 and Jeremiah 34 - viewing the loss of freedom as a result of disobedience to God's commandments. The discussion highlights the fact that political freedom could not be regarded as a basic right of a people in the time of the Old Testament. Freedom in their own land was regarded as a gift of God to Israel. To retain this freedom the people had to obey God's commandments; otherwise this freedom could be lost. Deuteronomy 28 indicates that obedience will result in blessings, while disobedience will result in punishment. Freedom in their own land is mentioned together with the blessings and the curses. Jeremiah 34 proceeds from the same premise, but relates the loss of freedom to the people's failure to release their slaves.
\end{abstract}

\section{Inleiding}

Honderd jaar na die Tweede Vryheidsoorlog bly die saak van vryheid 'n belangrike twispunt. Is volke in Suid-Afrika vry, of word sommige volke hulle vryheid ontneem binne die nuwe staatkundige bestel in SuidAfrika? Dit is sekerlik nie sonder rede dat een van die politieke partye wat in Suid-Afrika tans die steun van Afrikaners probeer kry, homself die 
Vryheidsfront noem nie. Staatkundige vryheid vir Afrikaners binne 'n eie land het waarskynlik 'n onbereikbare ideaal geword. Selfbeskikking op 'n ander wyse as staatkundig lyk ook taamlik problematies. 'n Eeu gelede het mense in Suid-Afrika ook 'n krisis oor hulle vryheid beleef - en so 'n krisis dwing tot nadenke. In die lig hiervan is dit noodsaaklik om die hele saak van vryheid in teologiese besinning aan die orde te stel. Hierdie artikel wil probeer om 'n Ou-Testamentiese perspektief op die saak van vryheid te bied, sonder om in alle opsigte antwoorde op die huidige situasie te wil vind. Op grond van die lig wat die Ou Testament bied, kan enkele opmerkings met betrekking tot die huidige situasie wel aan die einde gemaak word.

Alhoewel vryheid ' $n$ saak is wat in die Ou Testament besondere aandag kry, kom daar nie 'n woord vir vryheid in staatkundige sin in die Ou Testament voor nie (Olivier, 1997b:240). Ook die woord $\prod \in v \theta \in \rho / a$ in die Nuwe Testament het nie so 'n betekenis nie (Blunck, 1975:717). Die woorde wat in die Ou Testament dikwels met "vryheid" of verwante terme vertaal word ( en verwante woorde), word normaalweg in die konteks van slawerny gebruik. Tog speel die saak van vryheid in staatkundige sin wel ' $n$ belangrike rol in die Ou Testament - meermale verbind aan die besit van ' $n$ eie land. Bevryding kan inderdaad beskou word as een van die sentrale temas in Israel se belydenisse (Hulst \& Van Leeuwen, 1981:18). Die beloftes van God aan die volk Israel en hulle voorvaders het dikwels binne die raamwerk van die verbond gefunksioneer. Die vryheid van die volk Israel in staatkundige sin kan in die Ou Testament dus ook nie van die verbond losgemaak word nie. Hierdie artikel gaan in die besonder let op watter lig veral twee gedeeltes in die Ou Testament kan werp op die saak van vryheid in die raamwerk van die verbond. Die twee gedeeltes is Deuteronomium 28 en Jeremia 34:8-22.

Deuteronomium 28 bevat 'n lang reeks beloftes (seëninge) en strawwe (vervloekinge) wat onderskeidelik die gevolg sou wees van gehoorsaamheid of ongehoorsaamheid aan die bepalings van God se verbond. Die besit van 'n eie land en vryheid kom hierin ook aan die orde, verbind aan gehoorsaamheid aan die verbondsbepalings, terwyl ongehoorsaamheid verlies van land en vryheid sou kon beteken. In Jeremia 34 word die verlies van vryheid verbind aan die volk se optrede teenoor slawe, 'n verbinding dus van vryheid van slawerny en vryheid in die eie land. Albei hierdie gedeeltes moet verstaan word binne die raamwerk van die verbond, en spesifiek die plek van seën en oordeel in die verbond tussen God en Israel. Voordat die twee gedeeltes self bespreek word, sal hierdie raamwerk as agtergrond vir die bespreking aan die orde kom. 


\section{Die plek van seën en oordeel in die verbond}

Vir meer as twintig jaar sedert 1960 het heelwat navorsers aandag gegee aan moontlike ooreenkomste tussen die verbond in die $\mathrm{Ou}$ Testament en buite-Bybelse staatsverdrae uit die laaste twee millennia voor Christus. In hierdie navorsing het Deuteronomium heelwat aandag gekry, met besondere aandag aan die struktuur van die boek. Die afgelope aantal jare het belangstelling in die onderwerp afgeneem, hoewel dit soms steeds aandag geniet, soos byvoorbeeld in die onlangse werk van Steymans (1995). Vir die aanvanklike belangstelling in die moontlike verband tussen die staatsverdrae en die verbond in die $\mathrm{Ou}$ Testament was veral die werk van Mendenhall (1954a en 1954b) en McCarthy (1963) besonder belangrik. Vir die inhoudelike ooreenkomste tussen die strawwe in Deuteronomium 28 en die vasalverdrae van Esarhaddon het Frankena (1965) weer 'n besondere bydrae gelewer. Ook Fensham (1962 en 1963) het indringende aandag gegee aan die seëninge en strawwe in die buite-Bybelse verdrae en die Ou Testament. Hy onderskei veral twee hoofgroepe van vloeke, naamlik dié wat te doen het met die persoon van die oortreder en dié wat te doen het met die besittings van die oortreder. Die eerste groep vervloekinge handel oor sake soos dat die oortreder gedood sou word, nie 'n nageslag sou hê nie, siek of melaats sou word en dat sy lyk blootgestel sou word (Fensham, 1963:158-164). Die tweede groep betrek sake soos die vernietiging van die woonplek van die oortreder, natuurrampe en dat sy vroue aan sy vyand gegee sou word (Fensham, 1963:164-170). Die vloeke raak dus 'n wye verskeidenheid sake, waaronder oorlog, beleëring van 'n stad, hongersnood, ballingskap en die vernietiging van lewe, gesinne, stede, huise en lande (Thompson, 1964:12).

Soms is hierdie soort navorsing misbruik om kategoriese uitsprake oor die ouderdom van Deuteronomium te maak (vgl. Kline, 1972:151). Die gevolg was natuurlik skerp kritiek op hierdie soort vergelykende studie, soos goed saamgevat deur Preuss (1982:63-74). Dit is onmoontlik om hier in alle detail op hierdie debat in te gaan. Persone se standpunte oor die waarde van die staatsverdrae vir die bestudering van die verbond in die Ou Testament hang dikwels saam met hulle siening van die ouderdom en die ontwikkeling van die verbondsgedagte in die Ou Testament (vgl. Hillers, 1969; Lundbom, 1996:297-298). Ten spyte van kritiek het hierdie soort navorsing belangrike insigte gebring oor die plek van seën en straf in die raamwerk van die verbond. In hierdie opsig speel Deuteronomium 28 'n besondere rol in die boek Deuteronomium. Ooreenkomste tussen die gedeelte in Deuteronomium en die oordele uitgespreek deur die profete het ook besondere aandag ontvang (vgl. byvoorbeeld Hillers, 1964). In die seën- en oordeelsuitsprake in Deuteronomium 28 speel 'n eie land en vryheid in die land ook 'n 
besondere rol, soos later aangetoon sal word. Steymans (1995) het meer onlangs ' $n$ omvattende vergelykende studie van die vloeke en seëninge in Deuteronomium 28 en die vasalverdrae van Esarhaddon gedoen. Hy bied 'n breë agtergrond vir die verstaan van seën en vloek in die Ou Testament. Steymans (1995:377) meen dat die vloeke in Deuternomium 28 minstens gedeeltelik inhoudelik afhanklik is van die vloeke in die vasalverdrae van Esarhaddon. Vir die doel van hierdie artikel is dit nie nodig om volledig op die saak van moontlike afhanklikheid in te gaan nie.

In die verbond was die belofte van die land wat die Here aan Abraham en sy nageslag sou gee een van die sentrale beloftes. Die Here sou aan die volk 'n land gee waar hulle onder sy heerskappy sou woon (vgl. Diepold, 1972:77-78 en Lion-Cachet, 1977:151-152). In die geskiedenis van die uittog uit Egipte was die belofte van 'n land ook een van die belangrikste aangeleenthede, indien nie dié belangrikste nie (vgl. LionCachet, 1977:223-224). Ook in die boek Deuteronomium bly die belofte van die land een van die heel belangrikste sake, soos blyk uit die herhaalde verwysing na die land wat die Here aan die volk gegee het (Lion-Cachet, 1977:224-225; vgl. ook Davies, 1989:350-351). 'n Mens kan inderdaad sê dat die gedagte van die land soos 'n goue draad deur die geskiedenis van die aartsvaders en in die boek Deuteronomium loop (Helberg, 1990:16). Tog moet die gawe van die land steeds as seën gesien word, en nie as iets waarop die volk geregtig was nie (Helberg, 1990:33; Davies, 1989:349-350). As deel van hulle antwoord op God se genade moes hulle aan God gehoorsaam bly (Davies, 1989:352). Daarom word die volk ook telkens gewaarsku dat hulle die land sou kon verloor (Helberg, 1990:33). Dit is ook 'n sentrale element in die verkondiging van die profete (vgl. Davies, 1989:353). Ongehoorsaamheid aan God, veral afgodery en die oortreding van God se gebooie, sou verlies van die land as straf tot gevolg kon hê (Helberg, 1990:66). Die land was ten nouste verbind aan sowel die verkondiging van oordeel as verlossing (Davies, 1989:354). Die besit van die land is dus afhanklik gestel aan gehoorsaamheid aan God se gebooie (Diepold, 1972:95).

Die hele saak van seëninge en vloeke (beloftes en strawwe) was in die Ou Nabye Ooste 'n baie bekende verskynsel, soos blyk uit onder andere die werk van Fensham, McCarthy en Hillers waarna vroeër verwys is. Die saak van vloeke en seëninge in die Ou Testament is indringend deur Scharbert (1958) bestudeer. Hy wys daarop dat verbonde meermale met vloeke bekragtig is. In dié proses is die onderhorige party se verbondstrou deur 'n selfvervloeking bevestig (Scharbert, 1958:4). Dit gebeur ook dat Jahwe self 'n vloek uitspreek oor die een wat die verbond verbreek, soos in Deuteronomium 29:19-20 en Jeremia 23:10 (Scharbert, 1958:5). 
Die Hebreeuse woord word in vervloekinge gebruik. In die geval van hierdie woord word vervloeking en verbanning dikwels verbind, soos in Genesis 3:14 (Scharbert, 1958:5-6). Die werkwoord word ook in Jeremia 17:5 gebruik (Scharbert, 1958:6). In Jeremia 17:5-8 word 'n goeie voorbeeld aangetref van hoe die vloek en die seën teenoor mekaar gestel word. Daar word naamlik gestel dat die een wat op mense vertrou, vervloek is, soos 'n kaal bossie in 'n droë gebied. Daarteenoor word die een wat op die Here vertrou, geseën en is hy, net soos die regverdige in Psalm 1, soos 'n boom langs die water geplant.

In die verdrae van die Ou Nabye Ooste het die vasal se land en vryheid ook 'n plek gehad. In die Hetitiese verdrae was die vloek- en seënformule dikwels heel kort, soos byvoorbeeld in die verdrag tussen Mursilis en Duppi-Tesub (Pritchard, 1950:203-205). Die vloek bepaal bloot dat as Duppi-Tesub ontrou word aan die verdrag, die gode wat die verdrag waarborg, hom, sy vrou, seun, kleinseun, huis, land en besittings moet vernietig, terwyl die gode hom en alles wat aan hom behoort, sal bewaar as hy getrou bly aan die verdrag. Soms word meer besonderhede gegee, waarin land en vryheid pertinent aan die orde kom, soos in die verdrag tussen Suppiluliuma en Mattiwaza (Pritchard, 1950:206). Daardie verdrag stel duidelik dat verdragsverbreking daarop sal uitloop dat daar geen vrede meer in die land van die vasal Mattiwaza sal wees nie. In die verdrag tussen die Assiriese koning Ashurnirari $V$ en Mati'ilu van Arpad word ballingskap uitgesonder as een van die vloeke vir die verbreking van die verdrag (Pritchard, 1969:96).

Sake wat hiervoor van belang is, kom veelvuldig voor in die vasalverdrae van die Assiriese koning Esarhaddon. In die geval van die verbreking van die verdrag word 'n groot aantal vloeke uitgespreek. Dit sluit in dat die vasalkoning se vyand hom sal oorwin. Dit sou onder andere beteken dat die vyandelike koning sy vroue sal oorneem, dat sy seun hom nie sal opvolg nie (paragraaf 42, Pritchard, 1969:102) en dat sy nageslag uit die land sal verdwyn (Pritchard, 1969:105).

Die seëninge en strawwe wat in die Ou Testament uitgespreek word, verbind aan die onderhouding of verbreking van die verbond, pas dus goed in binne die konteks van daardie tyd. Ook die land as gawe van God moet binne die raamwerk van die verbondsteologie beoordeel word (Diepold, 1972:102). Die sentrale plek wat die land - en daarmee saam 'n vrye bestaan in die land - in die beloftes van God aan die volk ingeneem het, maak dit goed verstaanbaar dat die land en vryheid ook in die gedrang kan kom as die volk die verbond sou verbreek. 


\section{Deuteronomium 28 en vryheid of die verlies van vryheid}

Deuteronomium 28 neem 'n besondere plek in die boek in. Von Rad het reeds voordat die vergelykende studie van Deuteronomium en die Ou Nabye Oosterse verdrae begin het, die boek se struktuur aan 'n verbondshernuwingseremonie verbind (Von Rad, 1958:34). Die boek bestaan dan, na aanleiding van die struktuur van die seremonie, uit vier dele, waarvan die seën en vloek van Deuteronomium 27 en 28 die laaste gedeelte is. Die saak van die struktuur van Deuteronomium kan nie hier in volle besonderhede bespreek word nie, maar daar is talle geleerdes wat die boek se struktuur aan die verbond verbind, met Deuteronomium 28 as die seën- en vloekformule in die verbondstruktuur (vgl. byvoorbeeld Kitchen, 1966:96-98; McCarthy, 1963:109-110, 120-121; Weinfeld, 1972b:66 en Craigie, 1976:24). Wat die formulering van die vloeke betref, het Frankena die ooreenkomste aangetoon tussen verskillende van die vloeke in Deuteronomium 28 en die vloeke in die vasalverdrae van Esarhaddon (vgl. Frankena, 1965:144-150). Hy beskou die Assiriese vloeke as die bron van die vloeke in Deuteronomium. Steymans (1995) sluit hierby aan en bied 'n omvattende bespreking van ooreenkomste tussen Deuteronomium 28 en die vloeke van die vasalverdrae van Esarhaddon en ander tekste uit die Ou Nabye Ooste.

In Deuteronomium 28 word 'n korter lys seëninge (1-14) en 'n langer lys vloeke (15-68) aangetref. Die seëninge en strawwe hou verband met veiligheid, voorspoed en welvaart in die beloofde land. Ook die behoud van die land speel 'n belangrike rol, iets wat direk verband hou met die onderwerp van hierdie artikel. Gehoorsaamheid aan die bepalings van God se verbond is die voorwaarde vir die ontvangs van die seën, terwyl ongehoorsaamheid op straf sal uitloop.

Die seëninge en die strawwe vertoon dieselfde patroon. Die twee gedeeltes word ingelei deur seëninge of vloeke met 'n vaste skema. Dit begin met die passiewe deelwoorde of , gevolg deur die persoon of saak wat geseën of vervloek word. Die twee inleidende gedeeltes bevat ook ooreenstemmende dinge wat geseën of vervloek word. So begin die seëninge met "Geseënd is jy in die stad" en die vloeke met "Vervloek is jy in die stad". In die twee stelle inleidings word die seën en die vloek kortliks saamgevat, terwyl die res van die twee gedeeltes in meer besonderhede ingaan op wat die seën en die vloek presies sal inhou. Die samevattings is omvattend en raak alle fasette van die lewe.

Die gedeelte wat die seën in meer besonderhede uitspel, raak veral drie sake: sekuriteit en veiligheid $(28: 7,13,14)$, vrugbaarheid van mens, dier en plant $(28: 8,11)$ en die besondere band tussen God en sy volk (28:9- 
10). Die land sal geseën word en die volk sal die oorhand oor sy vyande kry, dit wil sê, die volk sal sy staatkundige vryheid behou. Die seëninge wat hiermee verband hou, word konkreet geformuleer. As die volk die Here gehoorsaam, sal hulle oor ander volke regeer (28:1). Die volk sal nie net vryheid belewe nie, maar sal ook ander volke die vryheid ontneem. Dit hou in dat God se volk hulle vyande in die oorlog sal verslaan (28:7), dat hulle in 'n besondere sin God se volk sal bly (28:9) en dat hulle voorspoed sal bly beleef (28:13).

Die voorwaarde vir die ontvangs van die seën is gehoorsaamheid aan God se verbond. Die teëpool hiervan is dat ongehoorsaamheid oordeel sal beteken.

Die vloeke word in baie meer besonderhede as die seëninge uitgespel (veertien teenoor vier en vyftig verse). Soos wat die seën die hele lewe raak, doen ook die vloeke. Sommige van die vloeke is lank en ander weer kort. Die vloeke vertoon ook nie een of ander herkenbare patroon nie, maar hulle is duidelik baie omvangryk. God se oordeel sal die mense self tref - met siektes en plae. Dit sal ook die land tref - met droogte en hongersnood. Verskillende van die dinge wat aan die orde kom, is direk van belang vir die saak van die volk se vryheid in hulle eie land, of dan die verlies daarvan.

Deuteronomium 28:7 het gestel dat die Here die volk se vyande voor hulle sal verslaan. Ongehoorsaamheid sal egter beteken dat die volk voor die vyande verslaan sal word (28:25). Die gevolg sal wees dat hulle lyke op die oop veld sal bly lê $(28: 26)$. So sal die volk hulle vryheid verloor. Die vyande sal die volk se besittings en oeste oorneem (28:31 en 33) en, erger nog, hulle kinders sal ander volke se slawe word (28:32). Hulle sal hulle vyande moet dien (28:48). Hoe die volk teen hulle vyande sal verloor en watter verskriklike dinge hulle sal ervaar wanneer hulle in hulle stede beleër word, word in grusame besonderhede uitgespel (28:48-57).

Wat die behoud van die land betref, word ballingskap pertinent as een van die vloeke gestel (28:36-37). In die ballingskap sal hulle magteloos die spot van ander mense moet verduur. Steymans (1995:259-260) meen dat dié uitspraak in teenstelling staan met die res van die vloeke. So dui 28:38 daarop dat net die kinders gedeporteer sou word en nie die hele volk, soos in 28:36-37 nie. Hy beskou dié verse as 'n byvoeging uit die tyd van die ballingskap. Dit is egter nie nodig om volledige konsekwentheid in die vloeke te verwag nie. Die vloeke moet bloot gesien word as voorbeelde van dinge wat moontlik sou kon gebeur. In so 'n geval kan daar selfs teenstrydige moontlikhede wees. 
Diegene wat self nie in ballingskap gaan nie, sal moet toekyk hoe hulle seuns en dogters weggevoer word (28:41). Die volk was op die punt om die beloofde land in te gaan, maar as hulle nie aan God gehoorsaam bly nie, sal Hy hulle weer uit die beloofde land uitruk en hulle oor die aarde verstrooi (28:62-68). As 'n mens kyk na Deuteronomium 28:36 en 64 is dit vreemd dat Diepold (1972:103) sê dat ballingskap nooit as 'n straf in Deuteronomium voorkom nie. Ballingskap het gewoonlik die einde van 'n volk se bestaan beteken.

Deuteronomium 28 maak dit baie duidelik dat die volk se vryheid en hulle besit van 'n eie land nie maar 'n reg was nie. Dit was 'n gawe van God. Vir die behoud van land en vryheid sou hulle aan God gehoorsaam moes bly, anders sou hulle weer die gawe van vryheid en 'n eie land kon verloor.

\section{Jeremia $34: 8-22$ en die verlies van vryheid}

In Jeremia 34:8-22 kom twee aspekte van vryheid in een gedeelte na vore, naamlik die vryheid van slawe en politieke vryheid. Jeremia 34 beskryf twee episodes wat gedateer word in die tyd van Sedekia, die laaste koning van Juda. Alhoewel die twee gedeeltes elk ' $n$ eie eenheid vorm (1-7 en 8-22), hou hulle wel met mekaar verband. Die eerste episode word breedweg gedateer in die tyd toe Nebukadnesar teen Jerusalem oorlog gemaak het. Dit moet waarskynlik verbind word aan die tyd toe Nebukadnesar Jerusalem begin beleër het. Holladay (1989:234) plaas dit laat in die winter of vroeg in die lente van 588 v.C.

Hierdie eerste gedeelte van Jeremia 34 bevat 'n profesie van Jeremia teen Sedekia. Die volk sou die oorlog teen die Babiloniërs - en dus ook hulle vryheid - verloor. Sedekia sal self ook gevang word, maar sal nie deur die swaard sterf nie.

Die tweede gedeelte van Jeremia 34 beskryf die vrylating van slawe deur Sedekia en die volk in Jerusalem, gevolg deur 'n herroeping van die vrylating. Op grond hiervan is oordeel uitgespreek oor die mense van Jerusalem. Die oordeelsuitspraak verwys daarna dat Nebukadnesar van Jerusalem af weggetrek het, maar dat hy weer sal terugkom (Jeremia 34:21-22). Die vrylating van die slawe deur Sedekia en sy volgelinge kon moontlik ' $n$ reaksie gewees het op die profesie van Jeremia in die eerste gedeelte, as 'n poging om die Here se guns te wen. Die manier waarop die vrylating deur die koning gereël is, is 'n voorbeeld van 'n ooreenkoms wat deur 'n hoër party (die koning) 'n laer party (die volk) opgelê word (vgl. Nicholson, 1986:90-91). Die herroeping van die vrylating hou dan moontlik verband met ' $n$ tydelike opsegging van die beleg van Jerusalem deur Nebukadnesar. Dit het waarskynlik plaasgevind as gevolg van 'n 
opmars van die Egiptenare, as 'n mislukte poging om Jerusalem te kom help (vgl. Smit, 1965:83). Holladay (1989:239) plaas hierdie gebeure laat in die lente of vroeg in die somer van 588 v.C.

Vir die vrylating van die slawe gebruik Jeremia 34 die woord . Die woord word veral gebruik vir die vrylating van persone wat weens skuld wat hulle nie kon betaal nie, slawe geword het. lemand wat nie sy skuld kon betaal nie, moes óf sy kinders óf homself in slawerny verkoop om sodoende sy skuld te kon betaal (Olivier, 1997a:988). Jeremia 34 verwys waarskynlik na mense wat nie meer eiendom gehad het om na terug te keer nie (vgl. Wright, 1984:200), wat verklaar waarom hulle nie na die vrylating na hulle eie grond kon teruggaan en so die latere herroeping van hulle vryheid sou kon keer nie. Indien die gebeure afgespeel het tydens die beleg van Jerusalem, sou 'n terugkeer na grond buite die stad ook nie eintlik moontlik gewees het nie.

Die gedeelte in Jeremia 34 hou verband met bepalings oor die vrylating van slawe, wat aangetref word in Deuteronomium 15:1 en 12, Eksodus 21:2 en Levitikus 25:40-41 (vir 'n volledige bespreking van die gedeeltes, vgl. Wright, 1984). Deuteronomium 15 handel eers oor die afskryf van skuld (1-11) en daarna oor die vrylating van slawe (12-18). Dit gaan spesifiek oor Israeliete wat weens skuld slawe geword het. Die motivering vir hierdie vrylating is geleë in die verbondsverhouding tussen God en sy volk. God het die volk uit die slawerny van Egipte verlos en daarom moes daar by die volk 'n toegeneentheid wees jeens diegene wat slawe geword het (Hulst \& Van Leeuwen, 1981:42). Die gereelde vrylating van Hebreeuse slawe moes 'n deel wees van die volk se dankbaarheid vir hulle eie vryheid (Kloppers, 1993:238). Die woord word nie in Deuteronomium 15 aangetref nie, maar wel die uitdrukking , wat ook in Jeremia 34 aangetref word. In Eksodus 21:2 word 'n soortgelyke uitdrukking gebruik:

Die terminologie wat in Levitikus 25 gebruik word, is naby aan die terminologie in Jeremia 34 . In Levitikus 25:10 word ook gepraat van die uitroep van . Dit is 'n vrylating van slawe wat elke sabbatsjaar uitgeroep word, waarna Jeremia 34:15 pertinent verwys. Die vrylating behels ook 'n terugkeer na die familiegrond (Levitikus 25:41). Hierdie voorskrif is nooit na behore nagekom nie.

Wat nou volgens Jeremia 34 gebeur het, is dat Sedekia so 'n vrylating uitgeroep het. Daar is geen aanduiding dat dit in 'n sabbatsjaar was nie, alhoewel sommige geleerdes dit wel probeer aantoon (vgl. Holladay, 1989:239). Die bedoeling van die vrylating was om die Here se guns te kry, om sodoende die verlossing van Jerusalem en die volk uit die mag van Nebukadnesar te bewerkstellig (Jones, 1992:426). Die vrylating van 
die slawe kan inderdaad beskou word as 'n imitatio Dei (Kessler, 1971:107), waardeur die volk se vrylating uit Egipte nageboots word in 'n poging om God se guns te verkry. Wat verder besonder is, is dat die woord gebruik word om die ooreenkoms aan te dui wat oor die vrylating van die slawe tussen die volk en die koning gesluit is (Jeremia $34: 8$ en 10). Die woord word wel gebruik om verhoudings of ooreenkomste tussen mense aan te dui. In hierdie geval dui dit waarskynlik op 'n ooreenkoms wat die koning met die volk gesluit het (vgl. McConville, 1997:748; Weinfeld, 1972a:787-788). Dieselfde woord word natuurlik gebruik vir die verbond wat God met die volk gesluit het, soos in Jeremia 34:18, waar God verwys na die verbond as "my verbond". Soms kan die woord ook dui op spesifieke bepalings van die verbond, soos in Jeremia $34: 13$, waar die woord verwys na die spesifieke bepaling wat in vers 14 aangehaal word.

Die volk word verwyt dat hulle 'n ooreenkoms wat voor die Here aangegaan is, verbreek het. Jeremia 34:18-19 verwys na 'n seremonie wat met ' $n$ verbondsluiting of die sluit van 'n ooreenkoms verband hou. Hierdie seremonie het God as getuie gehad en die volk is daardeur verplig om die ooreenkoms na te kom (vgl. Kapelrud, 1982:140). Die volk het egter nie regtig bedoel wat hulle gedoen het toe hulle hulle slawe vrygelaat het nie. Hulle wou daardeur die Here se guns wen. Die feit dat die volk die ooreenkoms so maklik verbreek het, dui daarop dat hulle nie die vrylating van die slawe gesien het as 'n geleentheid om 'n verkeerde instelling te beëindig nie (Chavel, 1997:73). Hierdie regstelling was wel die doel van die finale redaksie van Jeremia 34 (vgl. Chavel, 1997:95). Toe die volk gedink het dat hulle optrede sukses gehad het, het hulle omgedraai en hulle slawe weer hulle vryheid ontneem. Op grond hiervan word die profeet na die volk gestuur om dit duidelik te maak dat hulle hulle vryheid sal verloor. Heel ironies word gesê dat die Here die volk sal vrymaak, maar dan vry vir oorlog, pes en hongersnood om hulle te tref (Jeremia 34:17). Deur die eeue heen het die volk nie hulle slawe die vryheid gegun waarop hulle geregtig was op grond van God se verbondsbepalings nie. Nou het hulle oënskynlik die slawe daardie vryheid geskenk, net om dit op verraderlike wyse weer van hulle weg te neem. Die gevolg hiervan sou hulle eie verlies aan vryheid wees (vgl. Wright, 1984:194).

\section{Slot}

Bostaande bespreking van Deuteronomium 28 en Jeremia 34 toon aan dat die politieke en staatkundige vryheid van die volk Israel in die $\mathrm{Ou}$ Testament nie 'n onvervreembare reg was nie. Vryheid in hulle eie land was 'n gawe van God. Die behoud daarvan is verbind aan hulle onder- 
houding van die bepalings van God se verbond. Deuteronomium 28 maak dit duidelik deur aan te toon dat gehoorsaamheid aan die verbondsbepalings seën tot gevolg sou hê. Ongehoorsaamheid sou egter die volk onder God se oordeel bring. Vryheid en die besit van die eie land kom pertinent aan die orde onder die seën en die vloek. Jeremia 34 gaan van dieselfde veronderstelling as Deuteronomium 28 uit, maar verbind die verlies van vryheid aan een spesifieke saak, naamlik die vrylating van slawe.

Staatkundige vryheid was vir baie eeue 'n voorreg wat eers die verenigde koninkryk en daarna die twee koninkryke van Juda en Israel geniet het. Deur hulle geskiedenis moes hulle egter daarvan bewus bly dat vryheid 'n voorreg was. Hulle kon onder hulle eie konings leef, maar meermale het daardie konings hulle op die verkeerde weg gelei. Hierdie verkeerde weg het op die ou end uitgeloop op die verlies van staatkundige vryheid. Hierdie verlies het egter nie die einde van die volk se bestaan beteken nie, maar het uitgeloop, veral vir die inwoners van Juda, op 'n beter verstaan van wat hulle verhouding met God eintlik moes beteken het. Gehoorsaamheid aan God se verbond was dwarsdeur hulle geskiedenis die pad waarop God hulle wou laat gaan. Op daardie pad sou hulle vrede met God beleef, selfs al sou hulle hulle vryheid verloor.

Die saak van vryheid geniet vandag besondere aandag in Suid-Afrika op grond van twee aangeleenthede, naamlik die herdenking van die Tweede Vryheidsoorlog en die veranderde politieke bestel sedert 1994. Die Ou-Testamentiese perspektief wat in hierdie artikel bespreek is, kan uiteraard nie direk op die situasie in Suid-Afrika vandag toegepas word nie. In die Nuwe-Testamentiese bedeling het geen volk die besondere posisie wat Israel in die Ou Testament gehad het nie. Tog sou 'n mens die afleiding kon maak dat vryheid in staatkundige sin (onafhanklikheid in 'n eie grondgebied) nie 'n basiese reg vir 'n volk is nie. Die voortbestaan van 'n volk vereis nie noodwendig staatkundige vryheid in 'n eie land nie. In die negentiende eeu het Afrikaners Afrikaners gebly, ten spyte daarvan dat hulle in verskeie state (Britse kolonies of onafhanklike republieke) gewoon het. Die neerlaag in die Tweede Vryheidsoorlog was eintlik net weer 'n nuwe begin, waarin Afrikaners in 'n nuwe staatkundige bedeling opgeneem is. In die Suid-Afrika van die jaar 2000 is Afrikaners weer deel van 'n nuwe bestel. Die nuwe bestel het 'n grondwet waarin sekere basiese regte verskans is en dit bied vir die mense van SuidAfrika die moontlikheid om hulle vryheid op 'n nuwe en verantwoordelike wyse uit te leef. Indien die nuwe bestel in chaos verval, sal vryheid in die ware sin van die woord steeds 'n illusie bly. In die nuwe bestel moet mense wat 'n bevoorregte posisie verloor het, nie bly hunker na wat 
verby is nie, maar met verantwoordelikheid werk aan die opbou van 'n land, om sodoende werklik diensbaar in God se koninkryk te wees. Veral gelowiges word opgeroep om eers God se koninkryk te soek, met die wete dat alle ander dinge daaraan onderworpe is.

\section{Bibliografie}

BLUNCK, J. 1975. Freedom. (In Brown, C., ed. New International Dictionary of New Testament Theology 1. Grand Rapids : Zondervan. p. 715-721.)

CHAVEL, S. 1997. 'Let my people go!' Emancipation, revelation, and scribal activity in Jeremiah 34:8-14. Journal for the Study of the Old Testament, 76:71-95.

CRAIGIE, P.C. 1976. The book of Deuteronomy. (New International Commentary on the Old Testament.) Grand Rapids : Eerdmans.

DAVIES, E.W. 1989. Land; its rights and priviliges. (In Clements, R.E., ed. The world of Ancient Israel. Sociological, anthropological and political perspectives. Cambridge : University Press. p. 349-369.)

DIEPOLD, P. 1972. Israels Land. (Beiträge zur Wissenschaft vom Alten und Neuen Testament 95.) Stuttgart : Kohlhammer.

FENSHAM, F.C. 1962. Maledictions and benedictions in ancient Near-eastern vassal-treaties and the Old Testament. Zeitschrift für die alttestamentliche Wissenschaft, 74:1-9.

FENSHAM, F.C. 1963. Common trends in curses of the Near-Eastern treaties and kudurru-inscriptions compared with maledictions of Amos and Isaiah. Zeitschrift für die alttestamentliche Wissenscahft, 75:155-175.

FRANKENA, R. 1965. The vassal-treaties of Esarhaddon and the dating of Deuteronomy. Oud-Testamentische Studien, 14:122-154.

HELBERG, J.L. 1990. Die verbondsvolk in sy verhouding tot die land. Potchefstroom : $\mathrm{PU}$ vir $\mathrm{CHO}$.

HILLERS, D.R. 1964. Treaty curses and the Old Testament prophets. (Biblica et Orientalia 16.) Rome : Pontifical Biblical Institute.

HILLERS, D.R. 1969. Covenant. The history of a Biblical idea. Baltimore : Johns Hopkins Press.

HOLLADAY, W.L. 1989. Jeremiah 2. (Hermeneia.) Minneapolis : Fortress.

HULST, A.R. \& VAN LEEUWEN, C. 1981. Bevrijding in het Oude Testament. Kampen : Kok.

JONES, D.R. 1992. Jeremiah. (New Century Bible Commentary.) Grand Rapids : Eerdmans.

KAPELRUD, A.S. 1982. The interpretation of Jeremiah 34,18ff. Journal for the Study of the Old Testament, 22:138-141.

KESSLER, M. 1971. The law of manumission in Jer. 34. Biblische Zeitschrift, 15:105108.

KITCHEN, K.A. 1966. Ancient Orient and Old Testament. London : Tyndale.

KLINE, M.G. 1972. The structure of Biblical authority. Grand Rapids : Eerdmans.

KLOPPERS, M.H.O. 1993. Verbond en sosiale prediking. Sosiale aspekte in die teologie van Deuteronomium. Skrif en Kerk, 14(2):236-248.

LION-CACHET, F.N. 1977. Die kontinuïteit van die Abrahamitiese verbond in die opset van die Sinaïtiese verbond. Potchefstroom : PU vir CHO. (Th.D.-proefskrif.)

LUNDBOM, J.R. 1996. The inclusio and other framing devices in Deuteronomy IXXVIII. Vetus Testamentum, 46:296-315. 
McCARTHY, D.J. 1963. Treaty and covenant. A study in form in the ancient Oriental documents and the Old Testament. (Analecta Biblica 21.) Rome : Pontifical Biblical Institute.

McCONVILLE, G.J. 1997. . (In VanGemeren, W., ed. New International Dictionary of Old Testament Theology and Exegesis 1. Grand Rapids : Zondervan. p. 747-755.)

MENDENHALL, G.E. 1954a. Ancient Oriental and Biblical Law. Biblical Archaeologist, 17:26-46.

MENDENHALL, G.E. 1954b. Covenant forms in Israelite tradition. Biblical Archaeologist, 17:50-76.

NICHOLSON, E.W. 1986. God and his people. Covenant and theology in the Old Testament. Oxford : Clarendon.

OLIVIER, J.P.J. 1997a. . . (In VanGemeren, W, ed. New International Dictionary of Old Testament Theology and Exegesis 1. Grand Rapids : Zondervan. p. 986989.)

OLIVIER, J.P.J. 1997b. II . (In VanGemeren, W., ed. New International Dictionary of Old Testament Theology and Exegesis 2. Grand Rapids : Zondervan. p. 238242.)

PREUSS, H.D. 1982. Deuteronomium. (Erträge der Forschung 164.) Darmstadt : Wissenschaftliche Buchgesellschaft.

PRITCHARD, J.B., ed. 1950. Ancient Near Eastern texts relating to the Old Testament. Princeton : Princeton University Press.

PRITCHARD, J.B., ed. 1969. The Ancient Near East. Supplementary texts and pictures relating to the Old Testament. Princeton : Princeton University Press.

SCHARBERT, J. 1958. 'Fluchen' und 'segnen' im Alten Testament. Biblica, 39:1-26.

SMIT, E.J. 1965. Die ondergang van die ryk van Juda. Amsterdam : Vrije Universiteit. (D.Litt.-proefskrif.)

STEYMANS, H.U. 1995. Deuteronomium 28 und die adê zur Thronfolgeregelung Asarhaddons. Segen und Fluch im Alten Orient und in Israel. (Orbis Biblicus et Orientalis 145.) Freiburg/Göttingen : Universitätsverlag/Vandenhoeck \& Ruprecht.

THOMPSON, J.A. 1964. The Near Eastern suzerain-vassal concept in the religion of Israel. Journal of Religious History, 3:1-19.

VON RAD, G. 1958. Das formgeschichtliche Problem des Hexateuch. (In Von Rad, G. Gesammelte Studien zum Alten Testament. München : Kaiser. p. 9-86.)

WEINFELD, M. 1972a. . Theologisches Wörterbuch zum Alten Testament 1:781808.

WEINFELD, M. 1972b. Deuteronomy and the Deuteronomic School. Oxford : Clarendon.

WRIGHT, C.J.H. 1984. What happened every seven years in Israel? Old Testament sabbatical institutions for land, debts and slaves. Part 2. Evangelical Quarterly, 56(4):193-201.

\section{Kernbegrippe:}

land

Ou-Testamentiese siening van vryheid

slawerny

verbond

vryheid 


\section{Key concepts:}

covenant

freedom

land

Old Testament view of freedom

slavery 